\title{
AGROTOURISM - LEGAL PROBLEMS AND IT PERSPECTIVES
}

\author{
Žaklina Spalević ${ }^{1}$ \\ Miloš Ilić ${ }^{10}$ \\ Vladimir Džamić ${ }^{3}$
}

DOI: https://doi.org/10.31410/tmt.2019.139

\begin{abstract}
The challenge we tried to address in this paper included the consideration of the current state of agritourism in the Republic of Serbia, as well as the possibilities for the improvement of this branch of tourism using information and communication technologies. The current status of agritourism is viewed from two aspects. The first aspect is the application of IT technologies in order to promote the tourist offer, while the second aspect is oriented towards legal norms governing the protection of intellectual property as well as the tourist protection. With the application of IT technologies, individual accommodation establishments that feature agritourism can be presented to a wider range of potential tourists. A better presentation of the existing possibilities undoubtedly leads to an increased number of visits. At the same time, it is necessary to regulate the protection of digital multimedia content created by tourists, as well as the possibility of their usage in promotion of accommodation capacities and tourist offer.
\end{abstract}

Keywords: Digitalization, Web presentations, Cloud, Intellectual property.

\section{INTRODUCTION}

$\mathrm{T}$ ourism, as an economy branch, cannot be seen as a separate phenomenon, nor as a combination of different economic fields. In general, tourism is a human activity that encompasses human behavior, the exploitation of natural resources, as well as the connection between people, the economy and the environment (Bull, 2002). The tourist offer of each region has developed over the years and is based on the historical, cultural and artistic sights of the place as well as the natural beauties. Recently, a completely new area of tourism has emerged, an area that is mostly based on the combination of natural beauty, traditional agricultural, traditional nutrition and accommodation authentic to the area in which they are located. Agritourism as a new area of tourism is recognized and developed by individual farms trying to find a new source of income, offering different services. Agritourism, village or rural tourism is a type of tourism where tourists go to villages or farms to experience rural life. The terms agritourism, farm and rural tourism are often mixed although they have different meanings. For example, farm tourism includes the participation of tourists in rural activities such as caring for animals and crops, cooking and cleaning, crafts and entertainment.

All three forms of tourism have common characteristics that are reflected in the attempt to bring tourists closer to farm or rural lifestyles. Also, in most cases, the tourists' diet is based on products grown on farmers' own plantations. Organic agricultural products are often used to supplement the enjoyment of life in a healthy environment. Identifying or differentiating be-

\footnotetext{
1 Sinergija University, Rade Banjičića, 76300 Bijeljina, Republika Srpska, Bosnia and Herzegovina

2 Academy of Southern Serbia - Collage of Agriculture and Food Technology, Cirila i Metodija 1, 18400 Prokuplje, Serbia

3 Singidunum University, Danijelova 32, 11000 Belgrade, Serbia
} 
tween rural and agritourism varies considerably between countries. In the US, the terms rural and agritourism are almost identical and both refer to vast rural areas with ranches and farms. In the countries of the European Union, differences in rural and agritourism are significant because rural areas have pronounced non-agricultural functions (forestry, hunting and fishing species, catering, crafts and more are developing). Rural tourism represents farm tourism in the broad sense, and agritourism represents farm tourism in the narrow sense. Farm tourism can be defined as a set of relationships and phenomena arising from the travel and stay of tourists in rural areas. Rural tourism is tourism that takes place in a rural area.

The rapid development of information and communication technologies (ICT) and the dynamic development of tourism have been correlated for years. Since the late 1980s, software applications and solutions have been created for tourism purposes, often referred to as e-tourism. Information technologies enhance the process of linking tourism supply and tourism demand in the market, thus giving a whole new dimension to the distribution of package deals. The global tourism market entails expanding its business to a global level, and thus establishing wider distribution channels to enable more efficient product placement (Viduka et al., 2013, p.79). There are a growing number of services provided to tourists in the tourism industry, based on the use of the Internet as the main communication channel. The use of specialized software applications compatible with modern electronic devices, as well as the interaction between tourists and tourist destinations, opens up a new dimension in tourism. In order to provide interaction with tourists and tourist destinations, a number of different applications are in use. Considered in the field of agritourism, since these are places that do not represent widely known tourist destinations and attractions, the use of information and communication techniques should enable the contents of this type of tourism to be offered to potential tourists.

The promotion of the tourist offers in general, as well as the offer given by the accommodation facilities belonging to the agritourism, are complemented by photographs and multimedia content created by satisfied visitors. It is for these reasons that it is necessary to legally regulate the protection of such media by intellectual property rights, since very often a large number of digital contents is taken over by tourism organizations in order to promote and make money. Agritourism, especially organized on rural households, also offers the possibility of actively involving tourists in the process of agricultural production. In most cases, tourists are not used to or familiar with agricultural production. Such organized activity can be particularly pleasant for tourists. However, it is necessary to take care of their safety during the activities. It is for these reasons that the participation of tourists in agricultural activities must be regulated.

The paper is organized as follows. The second part of the paper gives an overview of the development of agritourism, similarities and differences with the traditional concept of tourism in the world and in the Republic of Serbia. The third part of the paper presents a description of potential information and communication technologies that can be applied in order to improve promotion of the agritourism offer. The fourth part of the paper gives an overview of the legal norms applicable in the field of protection of digital works created during the stay of tourists with intellectual property rights, as well as legal norms in the field of occupational safety. The fifth part of the paper summarizes the availability of information on agritourism offer in the Republic of Serbia, as well as the degree of digitization of individual accommodation capacities. The sixth part gives the most important conclusions regarding the promotion of the agritourism position in the Republic of Serbia, as well as ideas for future work. 


\section{AGROTOURISM DEVELOPMENT}

Agritourism can be seen as one of the special forms of tourism that originates from the 19th century. Although it is not easy to define the bare beginning of agritourism, the numerous tourists who started visiting farm and rural areas during the 19th century defined the basis for the its beginning. The exact starting point of the emergence of agritourism cannot be determined precisely as people have always visited rural areas during their holidays. This applies to people who have had to migrate to urban areas for work, but spend vacations in the countryside. Viewed from the angle of accommodation capacities, summer houses, cottages and similar buildings are included in the list of objects intended for holidays on their own properties.

The development of agritourism from the domain of people's residence on their own estates to the domain of building more accommodation capacities and creating offers for domestic and foreign tourists began by recognizing such potentials. Small farmers or landowners have recognized the possibility of an additional income by providing catering services to visitors on their properties. In this way, they have established a link between agricultural production and the provision of services to visitors who wish to return to nature, to become familiar with the traditional way of farming, and to possibly participate in agricultural activities. This relationship has become particularly popular in areas where farming is done in the traditional way, without the use of pesticides and supplements (Karagiannis \& Stavroulakis, 2011, p. 299). Furthermore, the combination of farming and tourism brings even more visitors to farms and properties.

As stated earlier, agritourism can be defined in different ways. More specifically, the concept of agritourism around the world is accepted in its narrower or broader sense. In some cases, such a term refers to farm stay, farm visit, or visits to the properties where residents are involved in different types of farming. For example, this is the case with agritourism in Italy. Across the globe, agritourism activities include, for example, buying agricultural products directly from farms, participating in agricultural activities such as picking fruit, feeding animals, or lodging in traditionally furnished country houses on a bed and breakfast basis. Agritourism accommodation offers visitors the opportunity to feel the taste of local traditional cuisine. Visitors can also try natural medical products and get acquainted with the customs of the area that are often forgotten by people living in the cities (Exarhos \& Karagiannis, 2004).

In addition to activities that are strictly related to everyday life, visitors can experience various other types of recreation and entertainment. For example, agritourism is often complemented by cycling, hiking, mountaineering, horseback riding or swimming. Such additional facilities, which relate primarily to the exploitation of natural resources, are of particular importance to rural tourism. People's interest in holidaying in rural areas is increasing, mostly because of urban problems, which are reflected in overpopulation, air pollution, increased noise and distance from nature. Families with young children are increasingly turning to vacations in rural areas, so as to provide children with stay in nature. The increase in interest in the benefits of rural tourism was first recorded in the lands of Western Europe, then in North America and finally in other countries of Central and Eastern Europe (Vukovic, 2017, p. 53).

Depending on the way of realization, agritourism can be considered as eco-tourism. More specifically, eco-tourism can be considered as a tourist offer in the context of rural environments, with special emphasis on the natural environment as a tourist attraction, as well as on educating tourists on preserving the environment in which they are located. Ecotourism promotes the 
quality and regional development as well as the preservation of cultural heritage by educating visitors and minimizing their impact on the environment they are in (Arabatzis \& Grigoroudis, 2010, p.163).

Agritourism in all its forms has proven to be a powerful tool in the field of reactivation and revival of abandoned areas. In addition to accommodation fee, catering and entertainment activities, and the direct sale of local products and crafts, agritourism brings other beneficial effects, such as the restoration of architectural and cultural heritage. This is the case with certain Canaries areas. In addition to revitalizing forgotten gems of natural beauty, agritourism greatly contributes to improving the position of women in rural areas, opening up the opportunity for expression and advancement through the entrepreneurial spirit. Thus, in certain areas of Canaries and Greece, the possibility of improving the position of women by actively involving them in the process of preparing traditional dishes as well as home-made products has opened up.

Viewed from a farmer's perspective, the involvement of tourists in the process of agricultural production improved the social status of farmers in society. Surveys have shown that after active participation in agricultural activities, the beneficiaries of the agritourism offer offered by farms acquire a different opinion in agricultural producers and view them not only as farmers, but as canons and people who create healthier food through their work. In this way, the agrarian is no longer only a supplier of tangible, but also of intangible goods, especially those associated with culture, education, gastronomy, landscape and environment. The development of agritourism and its popularization have opened up a whole range of innovative activities. These activities do not relate very much to the service economy. The activities created in this way indirectly stimulated new types of employment. The very development of new activities and new jobs causes the development of special types of training as well as the fulfillment of the technical conditions (Lopez \& Garcia, 2006, p. 85).

In addition to all of the above, the importance of agritourism is reflected in the great contribution to the development of the local community. Opening new accommodation facilities, local cuisine restaurants, as well as completing the tourist offer for example with riding lessons, nature walks and many other activities undoubtedly means more working positions. The beginnings of the development of agritourism are usually oriented towards the employment of family members who started the business. However, the increase in supply unquestionably requires the recruitment of additional labor force, especially considering that agritourism almost always goes hand in hand with agricultural activities. It is for these reasons that the development of agritourism is an additional profit for the rural sector in which a specific tourist offer is established. New jobs and the revitalization of the rural area reduce the displacement of the population from the rural area to cities. The effect that the development of agritourism has on the stay of young people in the countryside is also very evident. In a sense, young people are crucial for the development of agritourism, because they are the source of new ideas for complementing and expanding the tourist offer. On the one hand, the life of young people is not only based on agricultural production, but largely agritourism gives the opportunity for the development of entrepreneurial spirit and contact with other people of the same or different culture, which influences the decision of young people to stay in the countryside. On the other hand, the development of agritourism is based on the enrichment of the tourist offer, the mutual association in order to create different tourist tours or connect a number of regions with similar cultural and agro-ecological characteristics, which is a credit to young entrepreneurs. 
The development of agritourism within rural areas, on the basis of all of the above, has a great tendency and influence on the development and revival of social life within remote mountain villages, which very often represents an urgent need for residents of such settlements. It is a well-known fact that the inhabitants of such revived settlements in which, until the beginning of agritourism, the main occupation was agriculture, a certain part of the money earned from agritourism invests in agriculture and its modernization.

Probably the most famous example of using rural tourism as a „tool” in the function of rural development is Austria. Despite the underdeveloped communal and transport infrastructure of the Alpine countryside in the 1950s, as well as stagnant agricultural production, by introducing agritourism Austria has become one of the leading European countries in the field of preserving rural households and families in mountain areas. The beginning of the policy that will enable such agritourism development is the „eco-social model” introduced by the Austrian Ministry of Agriculture in 1988. Farm tourism accounts for 1/6 of Austria's total overnight stays. Tourism organized in this way is characterized by a low price per night, which with a large number of nights brings a turnover of about 25000 euros per farm per year. About 15,500 rural households are engaged in agritourism services (Grgic et al., 2015, p. 61). Associations within unique organizations as well as promotions through the unique internet portal of each of the organizations for Austrian farmers meant $25 \%$ more revenue compared to farms operating individually.

The organized development of agritourism on the territory of Italy began in the 1970s. The significance of agritourism is reflected in the fact that in 1981 the Agritourism Act was adopted, which classifies Italy as the only European Union country with agritourism law, while other countries apply the general provisions of the agritourism law to the agritourism domain. Research shows that at the beginning of the 21st century, there were about 9314 farm households registered in Italy with over 135000 beds. One of the most famous agritourism regions in Italy is certainly Tuscany with $32 \%$ of all accommodation units in agritourism in Italy. Accommodation varies from a relatively small family farm or larger farms to twenty or thirty people. Many farmhouses also offer numerous activities for their guests: horseback riding, mountain biking and information on local hiking trails, Tuscan cuisine courses and wine tastings. This type of vacation can even include family lunches with the host family, grape or olive harvesting, or just simply enjoying a peaceful, intimate stay in nature. This means that friendly hosts open the doors to their homes and offer a rustic yet elegant accommodation. Tuscany is rich in agritourism that has significant historical value. Many of these places are old fortifications reminiscent of the battles between Florence and Siena hundreds of years ago. Many of these once elegant old villas belonged to aristocratic families.

Agritourism in the area of Greece, for example, has great competition in the other far more popular form of tourism. However, the first steps in establishing agritourism began after 1970. Greece is also among the few countries that use agritourism as the backbone of the social policy of promoting women in rural areas. Also, the reduced tax rate has significantly influenced the development of agritourism in rural areas. Greece has launched a number of projects over the years to coordinate activities related to the development of agritourism, as well as in the area of standardization and association. However, the projects designed in this way did not produce the expected results; tourism entrepreneurs have independently organized themselves and established a non-profit organization whose sole and primary goal is to coordinate activities, jointly enter the market and solve problems of each of its members. 
The large number of rural areas in the territory of the Republic of Serbia as well as the traditional farming are good preconditions for the development of agritourism. About half of the population of the Republic of Serbia lives in rural areas, while the largest number is those belonging to the group of small agricultural holdings with a country ownership of about 3.5 ha. However, the development of agritourism and the population of rural areas of the Republic of Serbia started not too long ago. The reason for this was the inactivity of the public sector, which considered small rural areas a problem rather than a resource that could be exploited, and consequently, for many years the subsidies were oriented towards large landowners, while small farmers were deprived of them. In addition, the centralization of jobs in large factory facilities is locally oriented towards cities, which, as a consequence, leads to the migration of rural population to cities. The newly created employment policy, fueled by heavy subsidies to the foreign industrial sector, is reopening factory plants within cities. The workers of such factories mostly consist of people from rural areas who go daily to work and return home by organized transport. Such job creation combined with poor agricultural policy of the Government of the Republic of Serbia and low prices of agricultural products leads to the abandonment of rural estates and the cessation of farming (Rodriguez, 2011).

Dealing with agritourism as an additional form of income in the Republic of Serbia can certainly be a chance to revive rural households. Compared to the neighbors as well as the EU countries, the number of rural households engaged in tourism as an additional form of income is far smaller and according to the data of the tourist organization of the Republic of Serbia it is slightly over 200. The activities of the Chamber of Commerce of Serbia, which adopted in 2017 a proposal to launch an initiative for granting registered agricultural holdings the right to collect and issue invoices for catering services provided, indicate that the number of households is actively increasing. However, registered agricultural holdings engaged in tourism are currently not entitled to charge for their services independently, but most often do so through tourism organizations, which significantly complicates business. At the session, a proposal was adopted to launch the initiative that registered agricultural holdings engaged in tourism, i.e. agritourism, remain under the direct competence of the Ministry of Agriculture, Forestry and Water Management, as is the case in Slovenia. A Panacomp organization was created as a kind of hospitality network. This network covers over 300 selected rural households and represents the realization of residence and tourist arrangements in rural households in the villages of Serbia with uniquely designed contents and special activities - picking fruits, vegetables and herbs, mowing, hay collecting, donkey or wild horse races, mountain bikes rides, colorful events and traditional festivals, tractor races, traditional culinary courses, bread mixing in the traditional way, home-baked bread dough, folklore schools and folk dance lessons, ancient traditions and workshops of handicrafts and old crafts, getting to know the rich cultural heritage, a bed and breakfast, half board or full board basis, made from exclusively local, locally produced ingredients and products.

In document "the Strategy of development tourism in the Republic of Serbia it is anticipated that rural tourism in 2015 will comprise $6.6 \%$ of the total number of tourist nights, with an estimated market potential of one million overnight stays and the participation of foreign tourists from $15 \%$ of the total number of overnight stays, which makes about 150000 (Vukovic, 2017, p. 53). However, practice has shown that the results today are still lower. In fact, due to the lack of a unique database of accommodation capacities of rural tourism, monitoring of the number of tourist arrivals and overnight stays was difficult. 


\section{ADVANTAGES OF USING IT TECHNOLOGIES IN PROMOTION OF AGRITOURISM}

Attracting potential visitors and tourists within rural areas in order to increase the number of visits and promote agritourism is not an easy task. In order to generate additional income in addition to farming and therefore to ensure a better quality of life, the hosts on the farms must pay particular attention to the quality of the holiday they provide to tourists. Also, as these are individual accommodations away from popular tourist destinations and hotel complexes, special attention should be paid to promoting the content and accessibility of information to a wider group of potential visitors. One way for global promotion is certainly to create websites for each of the households involved in the business of running agritourism. In this way, potential tourists can search according to a specific criterion or relevant area and, as a result, obtain useful information about the accommodation capacities or benefits that available (Andreopoulou et al., 2006).

The agrotourist product has to be based on an interactive presentation of data, so that the prospective visitor will be capable of finding relevant information about the region and its infrastructures (Papastavrou et al, 2005). In this context, people of the countryside are the protagonists of the endeavor for the formation and development of agrotourism. Their task is to motivate tired city people so that they spend their holidays in a meaningful and healthy way of life. By establishing creative websites, local people are capable of showing-up the natural and cultural elements of their community, thus attracting visitors for time intervals longer than 24 hours, and leading them to extend their vacation time in the area (Andreopoulou et al., 2006, p. 8). They may offer high-quality tourist products to people who wish to pass-by even for one day, or for the weekend, in order to win their gratitude and make them come again for longer. Purpose of the website is to offer a wide range of information, to develop an interactive data base about the locality and to promote local agrotourist activities.

Creating a website for the purpose of describing the activities that the household is engaged in as well as for the purpose of promoting the tourist offer can have a greater effect with mutual association. The greater availability of information can certainly be achieved through the participation of the state administration, local self-government and tourism organizations in order to promote the accommodation capacities of agritourism of the region as well as their offer. Practically after the accommodation establish web sites within which they present their offer, the web sites created in this way can be linked from the official web-sites of the local self-government on whose territory the person engaged in agritourism is located. Also, links to accommodation facilities can be added to the site of a tourist organization of a specific municipality or region in the country, as well as to the site of a tourist organization of the country itself. In this way, a potential tourist can search the potential location for their vacation from a tourist organization website, a website of a tourist organization of the city or a website of local self-government, and from these websites further obtain the desired information about tourist activities of the specific area and the accommodation capacities. This kind of organization is especially important when it comes to foreign tourists, especially those who want to visit a country, region or specific location for the first time. It is common practice that tourists first start their search by browsing a country's overall tourism offer in the hope of finding the desired information and tips. The web portal of both official organizations and the state administration and individual service providers should be full of information as well as multimedia contents that will show both the natural beauty and the participation of visitors in the activities offered by the accommodation units of the agritourism. 
Also, these web portals should contain detailed instructions on how to get to the desired location for both those arriving on their own transport and those arriving using public transport. Information as well as multimedia must be kept up-to-date in order to always be accurate and to best reflect the tourist offer.

Interconnection with the participation of state authorities through the implementation of projects for the digitization of agrotourism offers can also be done by creating a cloud within which to contain relevant information. Cloud computing is a set of standardized IT performance, delivered to customers online, on a self-service and pay-per-use basis. Cloud allows its users to use different applications without first installing them on computers, as well as accessing data from anywhere and any computer. For many users, cloud computing is a way to increase the capacity and performance of their own infrastructures without the initial investment and at low cost. Global trends show that more and more companies are opting for the introduction of some form of cloud computing (Viduka et al., 2013, p. 80). Based on the host location, cloud computing can be classified into four models: shared cloud, public cloud, private cloud and hybrid cloud. These four models share certain characteristics, but also completely different key characteristics.

The cloud-based agritourism e-services thus created offer information sharing opportunities between tourists, government and private travel agencies, hotels, insurance companies, etc. One of the uses of cloud tourism can be mobile applications for sharing information about tourist destinations. For example, a system can be based on the use of public cloud. The cloud infrastructure itself is accessed through one of the electronic devices (mobile phones, tablets, PCs) for the purpose of transmitting information to the cloud. The service can be organized so that users add information about the location they are in, such as the name of the location, food and drink information, the various activities the site offers, events and their impressions. The information can be in the form of multimedia messages, pictures and sound. Notification of newly added information is forwarded by the cloud service to all users of this service. After receiving a notification for new information, the user can view all the details using the downloaded application on their device. By analyzing the data sent within this service, state agencies for controlling the work of travel agencies, carriers and accommodation facilities can get more information about possible problems. For this reason, travel agencies should also be users of this service. Travel agencies can add to the cloud information for new tourists in the form of selected carrier, accommodation, as well as daily planned activities. Such information is forwarded to carriers, accommodation establishments and travel guides who, based on this information, can further organize their activities in order to provide the best possible service.

Using cloud computing in conjunction with tools based on GIS (Geographic Information System) and web services can be another way of promoting tourism potential so as to increase the number of tourists. This is how the GISCloud platform is created, which is actually a WebGis service that provides tourists with free information about a particular area or tourist destination. Services like these, base their information on the private data of Internet users who have voluntarily made them public. The general idea of such a service is to make it more accessible to everyday users of web technologies (Ilic \& Spalevic, 2017, p. 342). For this reason, the service can be linked to various social networks (Facebook, Twiter), image sharing platforms (FlickR, Panoramio) and video sharing platforms (Youtube, Vimeo).

There are two types of users within such services. The first type of users are tourists using the service themselves to get information about a locality or agritourism offer of a place. The second group of users includes all those users who supply the service with information about a place. Each 
user who delivers content to the service is given the opportunity to, in addition to sharing their impressions in the form of comments, pictures and videos, link specific content with an interactive map of the area or specific object (hotels, restaurants, attractions) to which the facilities are related. For example, the owners of facilities intended for accommodation of visitors can advertise their facilities through such a service. The power of such services is based on the availability of spatial data and the information they carry. Spatial data sharing by system users is a major feature that can improve their quantity and quality. The organization of data within a web portal or blog should also be of the highest quality so that users can easily find the information they need. The information can be divided into groups, for example: 1) tourist facilities, restaurants and hotels; 2) places to visit; 3) transportation; 4) cultural heritage; 5) site maps. In addition to searching and reviewing information, one of the quality features that a portal should have is a site-specific tour plan. A plan like this should offer the user an interactive map of sightseeing, places of interest, and attractions. The service could create plans based on user-selected parameters. Some of the parameters may be the duration of the visit, the time of day, etc. It is very important that the initiative to create such services should come from the tourism organizations of the place as well as from the Ministry of Trade, Tourism and Telecommunications of each of the countries with tourist potentials. In order to achieve the best possible implementation, a large number of organizations (IT experts, geographers, tourism scientists, local government) and individuals should take part.

Popular accommodation search services available worldwide are able to filter their offer based on a variety of criteria. Some of the criteria are precisely related to the type of accommodation, so objects belonging to the agritourism domain can be selected as a search criterion. This kind of opportunity should be exploited by the owners of the facility who are categorized as agritourism offer. Practically, in order to bring their contents closer to more potential tourists, property owners should open orders and place advertising on such services. Web services designed in this way enable the connection between the owner of the property and the tourists themselves. Tourists, using such services, have a certain degree of security when it comes to booking accommodation. Accommodation owners are responsible for the validity of the advertising content as well as the validity of the description of possible activities that are dusty to visitors during their stay in their accommodation.

\section{LEGAL ASPECTS OF AGROTURISM DEVELOPMENT}

Easier access to information is certainly one of the main consequences of the development of the Internet, but it has also brought simpler ways of infringing intellectual property rights. Lawmakers are failing to keep up with the dynamics of the development of the Internet, so today there is no effective enough mechanism to adequately address the amount of IPR infringement on the global network. Whether an infringement of a right has been committed on the Internet does not in itself change the method of protection, which is irrespective of the form of the infringement. Protecting against these types of violations requires a lot of work, on the ground', with many obstacles, because the Internet is an undefined expanse, without state borders. There is no specific type of protection for intellectual property rights when the infringement is committed on the Internet. In Serbia, the Intellectual Property Office is in charge of this area. Regarding the regulation, Serbia monitors the world and European intellectual property protection streams and regulates in a comprehensive manner all the areas that belong to it, and one of the laws regulating this area is the Law on Copyright and Related Rights ${ }^{4}$. The issue of

$4 \quad$ Law on Copyright and Related Rights, „Official Gazette RS“, no. 104/2009, 99/2011, 119/2012, $29 / 2016$ decision US and 66/2019 
the application of the law is a matter of case law, it requires a more extensive analysis and it is thankless to give a general and an objective assessment. One part of the region is already in the EU and another is aligning its legislation with a view to accession. The EU attaches great importance to this issue and is constantly improving regulation; however, infringement cases involving multiple jurisdictions is something that is not easy to resolve. With the development of the Internet, a large number of blogs, information portals and other sites have appeared, and with them the problem of publishing and downloading content in digital format without citing sources / authors.

Digital content acquisition should also be regulated when it comes to content posted by tourists as well as by owners of accommodation facilities. Practically, if the tourist has posted travel photos showing the accommodation facility, as well as the activities that the visitor had during the trip, the question is whether the owner of the facility is allowed to take those same photos without the tourists' consent and place them on his site as a form of advertising. A similar situation occurs when photos from the site of the owner of the property are taken by travel agencies or sub-agents for the purpose of promoting and selling accommodation facilities. In such a case, even if a tourist agrees to post their photos on the site of the accommodation owner, he certainly could not know that they would be taken over by an agency, and therefore did not give such consent. Not too often agencies do photo correction, which is unauthorized alteration. The Law on Copyright and Related Rights, as well as the applicable pavilions of the Republic of Serbia, do not clearly define whether or not the download of published photographs is a violation of intellectual property. If the photographs obtained in this way are used as advertising through a medium, the consequences can be far more serious. Due to the use of photographs without permission and payment, in recent years photographers have been increasingly suing the media in Serbia. The penalties are too high and call into question the survival of the media, especially the local ones, which barely survive without them (Urosevic, 2017). The court equally looks at the value of a photograph, for example, of a meal or tourist attraction and a criminal suspect. However, the fact that intellectual property is one of the chapters in Serbia's negotiations with the European Union, as one of the important areas whose legal regulation needs to be harmonized with European standards, especially in the light of changes that brought a digital age with almost innumerable opportunities for abuse. Serbia has made progress in this area, as the European Commission's 2014 report shows, but there is more work to do to reach EU standards.

Agritourism from the perspective of travel and health insurance of travelers and tourists is a special form of tourism. As one of the forms of visitors' interest in active involvement in the process of agricultural production, each visitor should have a travel and health insurance policy for the period of stay in the rural area. Also, if visitors are involved, for example, in the process of harvesting raspberries, feeding animals or working on farms, the hosts should take all necessary measures to protect them in accordance with the law on safety and health at work ${ }^{5}$.

The development of tourism in rural areas and therefore agritourism as a strategic goal of the Republic of Serbia is defined by the adoption of a series of legal documents, starting with the Law on Tourism ${ }^{6}$ to the National Rural Development Program from 2018 to 2020. The Law on Tourism defines the conditions and manner of planning and development of tourism, tourism organizations for promotion of tourism, tourist agencies, services in tourism, the Register of Tourism and other issues of importance for the development and promotion of tourism. The

\footnotetext{
5 Law on Safety and Health at Work, „Official Gazette RS“, no. 101/2005, 91/2015 and 113/2017 - other laws.
}

$6 \quad$ Law on Tourism, „Official Gazette RS“, no. 17/2019. 
National Rural Development Program 2018 to 2020 sets out the medium-term directions for rural development and describes in more detail the ways in which rural development measures are implemented for the 2018-2020 programming period. At the same time, this document is also in line with the strategic framework of the Common Agricultural Policy of the European Union for the period 2014-2020, taking into account the specific needs and priorities of the development of agriculture and rural areas of the Republic of Serbia. The adoption of the National Rural Development Plan was preceded by the adoption of a series of laws and sub legal acts. For example, the Law on Agriculture and Rural Development ${ }^{7}$ is the legal basis for the adoption of multi-annual planning documents in the field of agriculture and rural development. The aforementioned law prescribes the adoption of the National Rural Development Program for a programming period which may not exceed seven years, for the purpose of achieving the strategic goals prescribed by the Strategy of Agriculture and Rural Development of the Republic of Serbia for the period $2014-2024^{8}$.

Italy is the only country within the European Union with specific laws regulating agritourism. It is specific that on the basis of the law, agrotourism is considered as an agricultural activity. In Italy first modern agritourism activities appeared in 1960. At the beginning there were a number of problems. The problems encountered were conditioned by the lack formal regulations and the consequent struggles with the local branches of the Ministry of Interiors, the Ministry of Finances, and with the Health Ministry. Practically the fight between these ministries was fought at the level of insurance of tourists and payment of taxes. Based on this Ministry of Interiors was in charge of monitoring the movements of tourists. In the same time the Ministry of Finances advocated the introduction of taxes on persons providing services in the field of agritourism. At first, these taxes went beyond the possibilities of small hoteliers. Health Ministry was responsible for the health of the tourists. This ministry called for the adoption of legal frameworks for adequate health care for all persons residing in the accommodation capacities of facilities belonging to rural tourism. This was especially important because of the participation of tourists in activities on the farm or on agricultural land. The continuous pressure by the agricultural sector finally has led the National Parliament to issue the Law 730/1985. Six years after its adoption, this law was amended by the Law no. 06. This new Law recognized that agritourism is an agricultural activity, regulated for the value-added taxation and for income taxation purposes by the same rules that supervise all other agricultural activities. The law also introduced some restrictions on the view of number of rooms in accommodation objects, number of beds, number of seats at the restaurant, source of ingredients for the meals, etc.

It is also specific to the Italian territory that to the each of the 19 regions was given the opportunity to create its own legal norms based on the aforementioned law. In the process of adoption of legal norms, the possibility of minor deviations from the law was given, based on specificities of local agriculture, culture and traditions. Nowadays within the Rural Development Plans several actions for the expansion and improvement of agritourism have been co-financed by the European Union to local authorities, to groups and even to individual farmers. Funding covers feasibility studies, training courses and extension activities, rural museums, territorial promotion, etc. Thus, created legal frameworks and funding have facilitated the synergies between public and private actors (Santucci, 2013, p. 190). With the adoption of the Tourism Law new institute named farm holiday was created. This new institute combines traditional agricultural activities

Law on Agriculture and Rural Development, „Official Gazette RS“, no. 41/2009, 10/2013 - other law and 101/2016 Strategy of Agriculture and Rural Development of the Republic of Serbia for the period 2014 - 2024, „Official Gazette RS“, no. 85/2014 
with tourism, expanding the offer and conciliating the tourist activities with nature. Article 1 of Tourism Law defines agritourism as follows: "Agritourism activities are the reception and hospitality activities carried out by the agricultural entrepreneurs referred to in Article 2135 of the Italian Civil Code, including in the form of capital companies or persons, or associated with each other, through the use of their own business in connection with the farming, forestry and animal breeding activities" 9 .

Agrotourism in Greece, as it is mentioned above, has a relatively short history. Its roots can be found in various forms of rural tourism that are common in Greece and take place on religious holidays, and at weekends. "Farmers and agrotourism" was initiative that was also launched in the mid-1980s as a type of tourism for mountainous and less favoured areas. As in the case of Italy, the Ministry of Agriculture had a great influence on the development of agritourism. With the agrotourism development plan provided by the Greek Ministry of Agriculture priority of development was given to areas with declining economies or population, and to border and peripheral areas and those with little or no mass tourism.

Financial aid was provided by European Union measures, namely Regulation 797/85 for structural investments in agricultural holdings and the LEADER initiative. The financial support thus defined included farmers who wanted to develop agrotourism activities and met some standards. Based on adopted regulations farmers who live in mountain areas and islands (excluding areas with massive tourist sectors) can achieve greater financial subsidies. This supportive practice continued with Regulations 2328/91, 950/97 and 1257/99, which were subsequently replaced by 797/85 and the LEADER II and LEADER PLUS initiatives with minor changes. The decision from 2019. enacted by the Tourism Ministry and the Rural Development and Food Ministry introduces the requirements for the Special Agrotourism Seal (ESA in Greek) which is mandatory. So as to ensure regulated business activity, professionals in the sector demand activity codes from all agrotourism enterprises across the country.

As highlighted in the announcement of tourism ministry, agrotourism businesses in Greece belong to a sub-category of tourist enterprises and operate with a ministry-approved special seal. According to the decision, all agrotourism-oriented facilities including but not limited to farms and ranches offering such services are required, to take the necessary actions to obtain the seal. Furthermore, in order to set up an agrotourism enterprise, interested parties must be signed up in the Greek farmers' registry and be able to offer accommodation of up to 40 beds on or off farm or agricultural locations (Kizos \& Iosifides, 2007).

Throughout Greece, there are Regional Tourism Services managed by The Greek National Tourism Organisation whose major competences are: granting the special license of operation, keeping the pertinent tourism business register, inspecting/auditing tourism businesses and imposing sanctions in cases where there is a violation of the tourism legislation in force. The Special Agency of Culture and Tourism (organisational unit of the former Ministry of Culture and Tourism) is in authority for planning, coordinating, managing and monitoring the implementation of the National Development Plan of the Ministry of Culture and Tourism and its supervised bodies. In order to implement the national strategy for tourism, the Ministry cooperates with the competent bodies (e.g. Ministries of Infrastructure and Transport, Environment and

Franceschelli, V. From Tourism to Sustainable Tourism An Italian Perspective, Retrieved 20.02.2020. From: https://www.researchgate.net/publication/328561356_From_Tourism_to_Sustainable_Tourism_ An_Italian_Perspective. 
Energy, Hellenic Statistical Authority, Local Government Organizations, etc.) and coordinates the operation of the supervised entities (mainly the services of the Greek National Tourism Organisation and of the Hellenic Chamber of Hotels) ${ }^{10}$. The latest scheme in the field of unification of legal norms governing tourism in Greece is the codification of all laws and their digitization. All laws that fall under the responsibility of the ministry of Tourism - including rules involving hotels, travel agencies, tourist coaches, tourism education and special forms of tourism are now gathered in a database and will be available online through an efficient platform that will be accessible through the tourism ministry's website. Through the new platform, interested parties, including Greek tourism enterprises and professionals, co-competent ministries, chambers, regions, local authorities and civilians, will be able to access the legislation without the need to refer to older laws and anachronistic provisions. The systematization of Greek tourism laws is projected to be particularly useful for potential investors.

The enacted laws and regulations, as well as the strategies for the development of rural areas all over the world encompassed the development of agritourism as a kind of compound with agricultural production. The laws and legal regulations introduced in this way provide the legal basis for the development of tourist offer in rural areas.

\section{RESULTS OF RESEARCH AND DISCUSSION}

The current state of agritourism in the Republic of Serbia as part of the research was examined from the aspect of promotion of tourist potentials using electronic services. It is known that in the Republic of Serbia there are 328000 rural households that have up to 3 ha of land and are engaged in agriculture, which makes up 56\% of the total number of rural households. Such households are the right candidates to engage in agritourism as a supplementary activity of agricultural production with the aim of higher income and raising the quality of life. In order to determine the number of those engaged in agritourism, a survey was launched to guide potential tourists, which is an overview of the tourist offer of the Republic of Serbia and an overview of the offer of accommodation capacities using electronic search services in booking accommodation.

By browsing the web portal of the Tourist Organization of Serbia, it is very easy to find a list of households that deal with tourism in addition to agriculture. For each of these households, a brief description of the activities, accommodation capacities, as well as instructions on how to reach the household itself is given. The description of each household also contains the contact information of the owner in the form of his first and last name and telephone number. In order to see how many of the total number of households a web portal has been created and therefore better-quality information with its accommodation capacities and activities it offers, an analysis of these households was carried out. A comparison of the number of households with and without their own web sites by regions of Serbia is given in Table 1. Summarizing the results, it is concluded that the tourism organization of Serbia publishes 219 households dealing with agritourism. The total number of those who have their own website is 82 , which makes $37.44 \%$ of the total.

Table 1. Comparison of rural households with and without web sites by region of Serbia

\begin{tabular}{|l|c|c|c|c|}
\cline { 2 - 5 } \multicolumn{1}{c|}{} & Central Serbia & Western Serbia & Vojvodina & Eastern Serbia \\
\hline Total \# of objects & 22 & 24 & 27 & 9 \\
\hline
\end{tabular}

10 Division of Power, Greece - Tourism, Retrieved 20.02.2020. from https://portal.cor.europa.eu/divisionpowers/ Pages/Greece-Tourism.aspx 
In addition to the web portal of the Tourist Organization of Serbia, and in accordance with the tourist practice of finding accommodation using one of the most popular electronic services booking.com, as part of the research, the service was searched according to various criteria that match agritourism. The results obtained by type of accommodation facilities are shown in Table 2. Comparing the results obtained by searching the website of the tourist organization, as well as the site booking.com, it can be concluded that the approximate number of households is present on both portals. The number of households that have their own website linked to the web site of the tourist organization of Serbia is far less than the number of those who decided to use booking.com to promote their offer.

Table 2. Number of accommodations by type on booking.com

\begin{tabular}{|l|c|c|c|c|c|}
\cline { 2 - 6 } \multicolumn{1}{c|}{} & Vocation home & Home stays & Country houses & Farm stays & Resort villages \\
\hline Total \# of objects & 103 & 29 & 28 & 10 & 1 \\
\hline
\end{tabular}

A good example of quality promotion of agritourism is certainly the portal village.co.rs. The portal offers accommodation in Zlatibor, accommodation in Tara, Fruska Gora, Divcibare, Kopaonik and many other mountains of Serbia. Also, here you can find ideas for farm holidays. In the spring days and during the summer, rest and enjoyment through this portal can be sought at numerous accommodations on the Drina. The portal was awarded the Merit in the domain of promotion of the offer by the Tourist Organization of Serbia, which awarded to the Rural Tourism of Serbia the Tourist Flower - the largest national recognition in tourism - in the category Promotion of Serbia in the electronic and print media. Thanks to the results of Selo. co.rs, the National Association of Rural Tourism of Serbia is a member and active representative of Serbia in the European Federation for the Development of Rural Tourism EUROGITES. EUROGITES is a gathering of 28 professional organizations from 25 countries of the world that provide the opportunity to inform and choose an authentic rural holiday. Selecting Serbia as one of the Member States gives you an interactive map and a brief description of the following content, „Holidays on a farm in Serbia - an unforgettable experience. Spend your vacation in close contact with nature in the homey and hospitable surroundings of one of the tourist farms. The countryside offers ideal opportunities for sports and farms as well as excellent starting points for excursions around the country. Enjoy the specialties from the traditional cuisines of Serbia accompanied by excellent wines". Active membership of Serbia in such an organization increases the visibility of agricultural tourism capacities to foreign tourists. Therefore, it is realistic to expect an increase in the number of tourists located within the facility located in a rural area. Increasing the number of visitors as well as the income received by both domestic and foreign tourists will contribute to the development of awareness of rural households in the area of inclusion in the process of adaptation and construction of accommodation capacities and agrotourism.

\section{CONCLUSION}

Decades of migration from rural areas to cities for employment and livelihoods have led to a decrease in rural population and the abandonment of fertile land. The rest of the population, in order to provide better living conditions in addition to farming, and in line with the increasingly popular trend of holidays in nature and rural areas, began to deal with tourism. Agritourism, as a kind of combination of tourism and agriculture in this way, has found a significant place in the life of both the people in the countryside and the tourists seeking escape from the urban hustle and bustle in these environments. 
Significant potentials for the development of agritourism in the Republic of Serbia can be said to have been used to a small extent. The number of holdings in the territory of the Republic of Serbia engaged in this type of tourism has not changed significantly in recent years. The promotion of the farms included in the tourist offer is largely well organized by the Tourist Organization of Serbia. The disadvantages of the current promotion are reflected in the small number of households that own their own web portals, where they publish all relevant information regarding their offer. Also, a small percentage of local government web portals contain a section listing accommodation in their territory.

By adopting a series of legal regulations, as well as national rural development strategies, the Republic of Serbia is actively working on the development of these areas as well as on the development of tourism within these areas. Practice shows, however, that the adopted standards do not apply to the intended extent. Confirmation of the non-implementation of the activity plan is reflected in the lack of interest of state authorities in investing in rural infrastructure. For example, it is not uncommon for rural areas located only two to three kilometers from the center of the nearest town to have a restricted water supply system, a sewer system, and no sheltered infrastructure. These are the basic shortcomings of further development as well as the main reasons why tourists avoid coming to these areas, and therefore do not increase the number of tourists in such environments.

The potential of the Republic of Serbia in terms of natural beauties, healthy environment and the production of healthy agricultural products can be used as a basis for improving tourism offer and rural life. The active involvement of homeowners with regard to better promotion through the use of information and communication technologies, as well as with the state authorities in terms of creating better quality infrastructure, can significantly improve this tourism sector.

\section{REFERENCES}

Andreopoulou, Z., Athanasiadis, D., Papastavrou, A., \& Papastavrou, K. (2006). Identifying Drama's Prefecture as a Tourism Destination through the Presentation of its Natural Environment in the Internet. In Proceedings of International Conference on Telecommunications \& Multimedia TEMU, Heraklion, Crete, 5-7 July, 2006, (pp. 1-8).

Andreopoulou, Z., Theoharopoulos, D., \& Papastavrou, A. (2006), Contribution of the Internet in the Touristic Promotion of Mountainous Communities. Touristic (1), 8-18.

Arabatzis, G. \& Grigoroudis, E. (2010). Visitors' satisfaction, perceptions and gap analysis: The case of Dadia-Lefkimi-Souflion National Park. Forest Policy and Economics, 12(3), 163 172.

Bull, A. (2002). Economics of Travel \& Tourism. N. York: Wiley.

Exarhos, G., \& Karagiannis, St. (2004). Agrotourism. The Centre for Technological Research of Crete, CTR-Crete Publications.

Grgic, I., Zrakic Susac, M., \& Gudelj-Velaga, A. (2015). Agritourism in Croatia and some eu countries. Agronomski glasnik, 1(2), 61-74.

Ilic, M., \& Spalevic, Z. (2016). Application of electronic services in tourism. In International Thematic Monograph - Thematic Proceedings: Modern Management Tools and Economy of Tourism Sector in Present Era (336-344). Belgrade: Association of Economists and Managers of the Balkans with Faculty of Tourism and Hospitality, Ohrid, North Macedonia.

Karagiannis, S., \& Stavroulakis, D. (2011). Development of Agrotourism through the Application of Internet Technologies: Problems and Perspectives. In: M. Salampasis, A. Matopou- 
los (eds.): Proceedings of the International Conference on Information and Communication Technologies for Sustainable Agri-production and Environment (HAICTA 2011), Skiathos, September, 2011 (pp. 8-11).

Kizos T., \& Iosifides T. (2007). The Contradictions of Agrotourism Development in Greece: Evidence from Three Case Studies, South European Society and Politics, 12(1), 59-77.

Lopez, E.P., \& Garcia, F.J.C. (2006). Agrotourism, sustainable tourism and Ultraperipheral areas: The Case of Canary Islands. PASOS. Revista de Turismo y Patrimonio Cultural, 4(1), 85-97.

Rodriguez, J.P. (2011). Sustainable initiatives in marginal rural areas of Serbia: a case study of Dimitrovgrad municipality, Applied Studies in Agribusiness and Commerce-APSTRACT Agroinform Publishing House, 5(1-2), 7-13.

Santucci F.M. (2013). Agritourism for Rural Development in Italy, Evolution, Situation and Perspectives. British Journal of Economics, Management \& Trade, 3(3), 186-200.

Urosevic, U. (2017). Intellectual Property and Media Photos, Retrieved from: http://boom93. com/info/lokalne-vesti/38245/intelektualna-svojina-i-fotografije-u-medijima.html, date: 25.08.2019.

Viduka, D., Basic, A., Lavrnic, I. (2013). Cloud Computing As A Potential Solution In E-Business. Journal of Economics, Management and Informatics - BizInfo, 4 (2), 79-85.

Vukovic, P. (2017). Character and dynamics of development rural tourism in the Republic of Serbia. Ekonomika, 63(4), 53-60. 